\section{Parental occupation, coercive power, and behavioral compliance*}

\author{
WILLIAM PIVNICK \\ United States International University, San Diego, Calif. 92124 \\ and \\ JAMES T. TEDESCHI \\ State University of New York at Albany, Albany, N.Y. 12203
}

Forty fifth- and sixth-grade children of entrepreneurial and bureaucratic parents were faced with a simulated peer who intermittently sent threats to them during the course of a reiterated prisoner's dilemma. One-half of each group of children was assigned to high, and one-half to low-threat credibility conditions. Irrespective of parental occupation, children responded to the cost-gain features of the situation. Entrepreneurial children cooperated more frequently than did bureaucratic children. The latter result was interpreted as indicating that entrepreneurial children are more responsive to a positive norm of reciprocity.

A series of studies have attempted to link parental occupation to the behavior of children in conflict situations. Miller \& Swanson (1958) found that bureaucratic parents taught their children to be accommodative in conflicts and respectful of rules, while entrepreneurial parents stressed independence training and competitiveness. Crowne (1966) found that children of entrepreneurial parents were more competitive in a prisoner's dilemma (PD) game than were children of bureaucratic parents. Berkowitz \& Friedman (1967) found that, as compared with children of blue-collar workers and bureaucrats, children of entrepreneurial parents more often followed an economic model of behavior; in a helping situation, the latter children gave help only in proportion as they received help and according to Gouldner's (1960) norm of reciprocity.

The above findings indicate that entrepreneurial values stress conflict and competition but that fairness of exchange is important in reaching agreements, and that bureaucrats value accommodation and cooperation but that help should be given as a function of organizational need rather than personal need. A plausible hypothesis would be that when faced with an opponent who possesses superior coercive power, the children of entrepreneurial parents should be defiant in response to threats and more competitive in the interaction sequence than should children of bureaucratic parents. The present experiment employed a 2 by 2 orthogonal design to investigate the effects of parental occupation and threat credibility on the behavior of

*This study was supported by National Science Foundation Grant GS-27059 to the second author. We are grateful to Michael Majores and Richard Stapleton for their help in analyzing the data. preadolescent boys in a conflict-of-interests situation. Each boy was sent threats by a simulated peer (SP) intermittently during the course of a modified PD game. Threat credibility was defined as the proportion of punishments administered on those occasions when the $\mathrm{S}$ was noncompliant. Horai \& Tedeschi (1969), employing the above definition of threat credibility and utilizing adult Ss, found a direct linear relationship between credibility and behavioral compliance. Low- and high-threat credibilities were established in the present study.

Three basic hypotheses guided the study: (1) entrepreneurial children would be more defiant of threats; (2) both groups would be more compliant to high- than to low-credibility threats; and (3) bureaucratic children would be more cooperative on those interaction occasions when coercive power was not employed by the SP.

\section{SUBJECTS AND APPARATUS}

Three judges, all graduate students in social psychology, using the criteria set forth by Miller and Swanson, independently and unanimously agreed on the placement of 40 white fifth-and sixth-grade boys into two equal groups of entrepreneurs and bureaucrats. Bureaucratic and randomly to the $0 \%$ and $100 \%$ threat-credibility conditions by the single white male $\mathrm{E}$.

In order to foster the impression to the $S$ that he was participating in a two-person game with a peer, the $\mathrm{E}$ simulated communications with an alleged other $E$ by utilizing nonoperative earphones, a microphone, and a microcircuit switchbox. Three posters were hung on the wall in front of the desk behind which the $\mathrm{S}$ sat. On the left, a single printed message was displayed: "If entrepreneurial children were assigned you don't choose green on the next turn of the game, I will take 10 dollars from you." The middle poster presented the payoffs associated with the $P D$ in matrix form. The matrix values were $\mathrm{R}=4, \mathrm{~T}=5, \mathrm{~S}=-5$, and $\mathrm{P}=-4 .^{1}$ The right-hand poster displayed three messages: (top) "I will choose green on the next turn of the game," (middle) "I will choose red on the next turn of the game," (bottom) "I don't want to tell you what I will do." Play money with the denominations of $1,5,10$, and 20 dollar bills was used as concrete payoffs and was exchanged between $E$ and $S$ after each trial of the game. Finally, two $9 \times 12$ in. squares, one red (on the left) and the other green (on the right), were placed on the desk directly in front of the $S$.

\section{PROCEDURE}

After introducing himself and obtaining the S's name, the E explained the rudiments of PD play, referring to the displayed payoff matrix and engaging the $S$ in several practice trials until the latter thoroughly understood the relationship of joint responses and payoffs. The $\mathrm{S}$ was told that he was participating with a peer who was in another room with another $E$ so that they could not communicate with one another during the game. The child was then told that the "other boy" could send the single message on the left poster whenever he chose and that a reply must be chosen from the three messages displayed on the right-hand poster on every such occasion. It was explained that the $\mathrm{S}$ could not initiate communciations but that he was constrained to reply when the "other boy" chose to initiate communications. The fact that the penalty threatened in the message could be imposed and that when ordered to do so by the "other boy" the $E$ would be obliged to take $\$ 10$ away from the $S$ was explained. The $S$ was lent $\$ 200$ in play money, told that the loan would have to be repaid at the conclusion of the game, and informed that all winnings were exchangable on a $\$ 1$ to one $M \& M$ candy basis.

At the end of each choice of game strategy or reply message by the $\mathrm{S}$, the $E$ announced the decision into the microphone and feigned listening before announcing what the "other person" allegedly did. Play money was either given to or taken away from the $S$ depending upon his responses and the preprogrammed responses of the SP. The threat message was "sent" to the S 19 times and about evenly spaced over the 100 game trials. The SP always competed on those trials to which the threat message pertained. Thus, on threat trials, the $\mathrm{S}$ was placed 
in a least-of-evils choice situation. If the $\mathrm{S}$ chose to comply by making the green (cooperative) choice, he was exploited and lost $\$ 5$. But if the $S$ chose to defy the threatener by making the red (competitive) choice, the former lost $\$ 4$ and then was vulnerable to the punishment option provided the SP on those occasions when the $\mathrm{S}$ was noncompliant. In the $0 \%$ threat credibility condition the SP never exercised the option to penalize the $\mathrm{S}$, while in the $100 \%$ threat credibility condition the SP always exercised the option to penalize the $S$. On the nonmessage (or threat-irrelevant trials), the SP was programmed to be $50 \%$ cooperative on a predetermined and random basis.

At the conclusion of the game, the cumulated winnings were counted and the original loan was repaid. Each S was promised that he would receive his $M \& M$ candies at the conclusion of the experiment. Losers were given a consolation prize of $10 \mathrm{M} \& \mathrm{Ms}$ and thanked for their valuable help in developing the "new game." Each S was then debriefed and returned to his classroom.

\section{RESULTS \\ Behavioral Compliance}

A 2 by 2 analysis of variance was utilized in analyzing each of the dependent variables of the present study. Only a threat-credibility main effect was obtained on the frequency with which Ss did as requested by threat messages $(F=15.249$, $\mathrm{df}=1 / 36, \mathrm{p}<.001)$. Ss in the $100 \%$ credibility condition were more compliant $(\overline{\mathrm{X}}=13.45, \mathrm{SD}=2.58)$ than $\mathrm{Ss}$ in the $0 \%$ credibility condition $(\overline{\mathrm{X}}=9.0, \mathrm{SD}=4.32)$.

Cooperative Responses

The frequency of green choices on nonmessage trials constituted the measure of cooperativeness. Only the effect of parental occupation was significant on this measure $(F=4.886$, $\mathrm{df}=1 / 36, \quad \mathrm{p}<.05$ ). Children with entrepreneurial parents were more cooperative $(\overline{\mathrm{X}}=31.65, \quad \mathrm{SD}=11.60)$ than were children with bureaucratic parents $(\bar{X}=22.20, S D=14.85)$.

Communicative Behavior

No effects were found on the frequencies with which Ss sent Reply Messages 1, 2, or 3 .

A measure of prevarication was obtained for each reply stating the S's intentions. The proportion of times the Ss did as they said they would constituted the measure of truthfulness. A main effect of threat credibility was found on the truthfulness with which the compliant message was used $(\mathrm{F}=8.814$, $\mathrm{df}=1 / 36, \mathrm{p}<.01)$. Ss in the $100 \%$ credibility condition were more truthfully compliant $(\overline{\mathrm{X}}=.776$, $\mathrm{SD}=.201$ ) than were $\mathrm{Ss}$ in the $0 \%$ credibility condition $(\bar{X}=.519$, $S D=.327)$. A threat-credibility main effect was also obtained on the truthfulness of Ss when they utilized the defiant message ( $F=4.081$, $\mathrm{df}=1 / 36, \mathrm{p}<.05)$. Ss in the $0 \%$ credibility condition were more truthfully defiant $(\bar{X}=.601$, $\mathrm{SD}=.281$ ) than were $\mathrm{Ss}$ in the $100 \%$ credibility condition $(\overline{\mathrm{X}}=.362$, $\mathrm{SD}=.333)$. No effects of parental occupation or of the interaction term were found in the analyses of truthfulness.

\section{DISCUSSION}

The results disconfirm Hypothesis 1 since parental occupation was not related to reactions to coercive power. There was a direct relationship between threat credibility and behavioral compliance in confirmation of Hypothesis 2. The only effect of parental occupation upon the behavior of the children found in the present experiment was that entrepreneurial children cooperated more often on nonmessage trials than did bureaucratic children, a result that directly contradicts Hypothesis 3 .

The responses of both groups of children to coercive power were rationally related to costs and gains. The greater the costs for noncompliance, the more compliant the Ss were. In the $0 \%$ credibility condition, the Ss were a little less than $50 \%$ compliant, while in the $100 \%$ credibility condition, Ss were $70 \%$ compliant. The manner in which Ss used reply messages was also consistent with economic concepts of rationality. Ss in the $100 \%$ credibility condition incurred no additional costs by being honest in announcing their impending compliance and did not risk making the powerful opponent angry by prevarication or by verbal defiance. Tedeschi, Bonoma, \& Lindskold (1970) found that Ss who were the sources of contingent threats were less likely to exploit a simulated target who honestly made an announcement of intention to comply than they were a target who followed his announcement of compliant intentions with defiant behavior. Thus, open and honest compliance to a threatener who is exploitative does offer the possibility of converting the exploiter into a more accommodative or benign threatener. On the other hand, Ss in the $0 \%$ credibility condition could better afford to lie about their intention to comply to the SP's demands because it cost them nothing and they could hope to lure the apparently "soft" and irresolute opponent into making a cooperative response and then exploit him.

Furthermore, $S$ in the $0 \%$ credibility condition were more truthfully defiant of the source's coercive power attempts than were Ss in the $100 \%$ credibility condition. Open and determined defiance by the target has been shown to have the effect of reducing the number of threats sent to him by a source of coercive power (Tedeschi, Bonoma, \& Lindskold, 1970). Ss in the $0 \%$ credibility condition could not know that prior $E$ plans, rather than his own verbal defiance, prevented the SP from punishing noncompliant behavior. Thus, a kind of superstitious behavior developed. The Ss in the $100 \%$ credibility condition, on the otherhand, could not be successful in their attempts to deter the threatener by open verbal defiance; they were punished for such behavior and were thus discouraged from engaging in it.

The finding that entrepreneurial children cooperated more than did bureaucratic children was in direct contradiction to the results obtained by Crowne. The difference in findings is probably attributable to the fact that the present study modified the PD by introducing communications between the players, while Crowne did not. In the PD, it is not clear that any norms govern behavior and the situation may often be interpreted by Ss as one of pure conflict. They therefore react in an attempt to best their opponent and ignore the potential for mutual gains. However, when communications are allowed between persons, particularly when the messages exchanged are either threats or promises, it apparently becomes more clear that norms of reciprocity, trust, mutual coordination of behaviors, deference patterns, and so on become relevant. The above reasoning led to the interpretation of the behavior of the entrepreneurial children according to the norms evoked and made salient for them in the situation. Berkowitz \& Friedman (1967) found that such children were less concerned than bureaucratic children with winning or losing a game and were more cooperative on a tit-for-tat basis than were the latter Ss. If the message-modified $P D$ is laden with normative cues, as seems likely from the evidence and if entrepreneurial children are more likely to respond on the basis of a norm of reciprocity than are bureaucratic children, then the former should more closely match the level of cooperation of the SP than should the latter. There were 100 trials in the experiment, 19 of which were threat-relevant. Of the 81 nonmessage trials, the SP cooperated 41 times. The entrepreneurial children cooperated 32 times on the average, while bureaucratic children cooperated only 22 times on the nonmessage trials. If the cooperative responses made under 
coercion are also counted, the entrepreneurial children $(\overline{\mathrm{X}}=43.5)$ almost perfectly matched the cooperations of the SP, while the bureaucratic children cooperated $(\bar{X}=32.8)$ about $22 \%$ less often than did the SP. When the SP cooperated, the $S$ was sure to win some money on that trial. It appears, therefore, that entrepreneurial children were helpful to the SP to the degree that the latter was helpful to them, while bureaucratic children were more competitive and apparently more concerned with the goal of winning the game.

REFERENCES

BERKOWITZ, L., \& FRIEDMAN, P. Some social class differences in helpin behavior. Journal of Personality \& Social Psychology, 1967, 5, 217-225.
CROWNE, D. P. Family orientation, level of aspiration, and interpersonal bargaining. Journal of Personality \& Social Psychology, 1966, 6, 641-645.

GOULDNER, A. W. The norm of reciprocity: A preliminary statement. American Sociological Review, 1960,25 . American

HORAI, J., \& TEDESCHI, J. T. The effects of credibility and magnitude of punishment upon compliance to threats. Journal of Personality \& Social Psychology, 1969,12,164-169.

MILLER, D. R., \& SWANSON, G. E. The changing American parent. New York: Wiley, 1958.

RAPOPORT, A., \& CHAMMAH, A. M. Prisoner's dilemma. Ann Arbor: University of Michigan Press, 1965.

TEDESCHI, J. T.. BONOMA, T., \& LINDSKOLD, S. Threatener's reactions to prior announcement of behavioral compliance or defiance. Behavioral Science. 1970, 15, 171-179. NOTE

1. Notation follows Rapoport Chammah (1965). the organism perceives in a more articulate manner. For instance, parts are more easily distinguishable from the whole. In terms of a perceptual model, hierarchic integration implies flexible perceptual activity. Developmental theory would contend that this type of activity is concomitant with increased articulation, not globality. Globality implies rigid perceptual activity.

In an effort to explain the perception of geometric illusions, developmental theory would maintain that younger organisms (children) are at a lower level of perceptual development; hence, they perceive more globally. In the case of the Poggendorff illusion, they are less able to distinguish the oblique line from the parallel lines; hence, a relatively large illusion results. On the other hand, older organisms (adults) are at a higher level of perceptual development; hence, they perceive more articulately. In the case of the Poggendorff illusion, they are more able to distinguish the oblique from the parallels; hence, a relatively small illusion results. So far, a developmental model of perception appears capable of explaining the finding that the magnitude of the Poggendorff illusion decreases with age. Now, how would the apparent specificity of the successive trials effect be explained?

It is important to understand that the basic tenet of Werner and Wapner's developmental theory is essentially a two-factor concept: (1) articulation,

and (2) integration. It is asserted here

Fig. 1. The Poggendorff illusion.

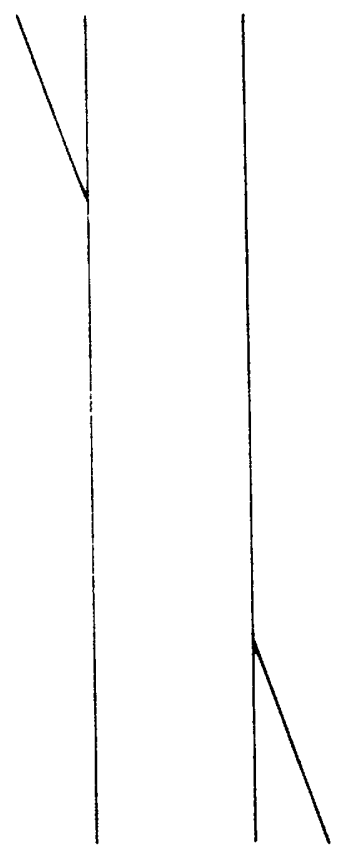

to

* Requests for reprints should be sent to the Department of Psychologv. University of Manitoba, Winnipeg 19, Man., Canada. repeated measures. Interestingly, it has been found that the illusion does not change with successive trials when children serve as Ss (Pressey \& Sweeney, 1970). However, Pressey \& Sweeney (1969) reported a successive trials effect with adult Ss. To date, the fact that the successive trials effect appears to be specific to adults has not been explained.

The developmental theory of Werner (1961) and Wapner \& Werner (1957) provides a perceptual model for an explanation of the apparent specificity (or interaction) of the successive-trials phenomenon with age. The basic tenet of Werner and Wapner's developmental theory is as follows: as the organism develops (grows in age), its functioning becomes increasingly articulate; concomitantly, its ability to integrate data hierarchically increases. In terms of a perceptual model, developmental theory would maintain that initially the organism perceives in a somewhat global (or inarticulate) fashion because the organization of its perceptual processes is relatively undifferentiated and consequently more homogenous. With an increase in age (development), 